\title{
Using Video Lectures to Make Teaching More Interactive
}

\author{
$\underline{\text { doi:10.3991/ijet.v5i2.1156 }}$ \\ M. Ronchetti \\ Università di Trento, Trento, Italy
}

\begin{abstract}
Having worked for a long time with videolectures, we devised a new teaching model that makes use of the recorded videos to free the teacher from part of his work and allowing him to concentrate his efforts on a more effective and involving teaching strategy.
\end{abstract}

Index Terms-Blended learning, Video lectures.

\section{INTRODUCTION}

Video lectures are becoming more and more popular, especially since important educational institutions such as Princeton and MIT started collecting and making public numerous recordings. Only a few years ago such a perspective was practically impossible [1]. We started long ago playing with the idea of recording lectures [2], and over the last 6 years we collected a relatively large number of video-lectures. We also produced a tool for recording videos synchronized with PowerPoint slides, and made it freely available.

The main advantages we viewed in the use of videolectures were the ability to

a) help working-students by bridging the gap given by their absence during regular lectures;

b) support regular students by giving them the opportunity to recover lectures lost due to forced or elective absence;

c) assist students having difficulties with the lecture's spoken language;

d) give students a mean to review critical sections and check their notes.

We found out that the navigability of the lectures given by some kind of semantic markups was precious in allowing students to quickly find the relevant sections, in case they only wanted to review a particular portion of some lecture. These results were in-line with the available literature (for a review, see [6]).

Although students typically appreciate this kind of service, the most obvious disadvantage of this technological choice is that the level of interaction between student and teacher or student and colleagues is zero. Even though this is not much worse than the interactivity level achievable in crowded classes, it is certainly not improving the traditional lecture model. Pursuing an electronic enhancement of the passive learning by means of (shared) annotations of learning materials has been attempted (see e.g. [3]), but does not radically solve the problem of improving the quality of students' participation and understanding.

On the other hand, also the traditional learning model based on frontal lectures held in class corresponds gener- ally to a passive student approach, and as such it has been highly criticized. Constructionist (see e.g. [4] for a general discussion of learning theories), and more recently, connectivist [5] approaches have been suggested as alternatives, and sometimes they have been used as theoretical frameworks in e-learning systems. Unfortunately these approaches often are either difficult to apply to large audiences, or they require much more time (and hence are more expensive). Therefore still today the large majority of higher education institutions still rely on the traditional frontal lecture model.

The idea we propose in this paper is that video-lectures can be used to change the style that the teacher uses in class, allowing for a more effective teaching. In section 2 we present our model. In section 3 the experiment we run, and discuss its evaluation. Finally, we draw our conclusions.

\section{THE MODEL}

We will focus here on basic courses. For most of these courses, the content does not dramatically change from one year to the next, and it can even remain almost exactly the same for a few years. The role of the teacher is to guide the class through the syllabus: if the class is composed by only a few students, then the teaching/learning pace may be different in different years because of statistical fluctuations in the students preparation and ability. If the number of students is relatively large (i.e. at least 50 or 60 students), as it often happens in basic courses, the statistical differences between different years are likely not to be significant. Often hence a course tends to be more o less a mere repetition of the previous edition. In such scenario, video lectures can become more than just an auxiliary instrument, as we shall propose in the following.

The Bologna process defined the concept of Formative Credits, used for mutual recognition in the European Credit Transfer and Accumulation System (ECTS). In all participating countries, one academic year corresponds to 60 ECTS-credits that are equivalent to $1500-1800$ hours of study: hence one credit corresponds to 25-30 hours of work. In the case of frontal lectures, it is customary to assume that approximately one third of the time is spent in class, while two thirds correspond to individual (or group) study. This means that the teacher helps the student only during one third of the learning process. Hence, in a course based on frontal lectures, the teacher's role is mostly focussed on the first part of the learning process, i.e. in the presentation of the material.

A possibility for a change is to move the role of the teacher more towards a coaching or tutoring approach. 
This is however known to be very time-consuming and costly.

Some teachers require students to do some work before coming to the classroom lecture, so that the lecture can resemble more a discussion than a soliloquy. However, in this way the role of the teacher as a facilitator in the introduction and explanation of concepts gets lost. Here is where the availability of videos can make a difference. In our model, first the students spend time assisting at the traditional lecture given by their teacher, and then they meet again the teacher for in-depth discussion, clarifications and focussed exercises. Apparently this doubles the teacher's load - but this is the point where videos come into play. Before coming to class, students assist (at home or wherever they want) at the recorded lecture with their professor. The teacher hence can give exactly her/his own perspective and imprint to the course. Then, in class, the teacher can spend the whole time interacting with the students, verifying their comprehension, proposing questions and clearing doubts.

At the end of this process, students will have spent twice as much time with the teacher, and half of this time they have really been interacting with her/him. The teacher is free from the duty of "passing knowledge" and "covering the syllabus" and can really concentrate on deepening the understanding. Moreover, s/he knows that the presentation of the learning material has been done exactly fitting her/his style, because it was done by her/himself!

Let's now discuss an important point, i.e. how the lecture was previously recorded. There are essentially two options: the first is to work in a "sterile environment" while the second is to do it on "the battlefield". The first choice corresponds to giving the lecture in a neutral environment, in front of a video camera (and possibly with an "art direction"). Such lectures, although polished and professionally looking, are generally extremely boring. The main reason is that the teacher has no feedback from real students.

The second option is to record real lectures given in the classroom. The teacher has constant feedback from the students - even if they do not speak. S/he can see the faces, understand if s/he has being boring, if students need to be cheered up with a mot of spirit, if anything needs to be repeated using yet another metaphor or by using one more example. This condition, which makes the real difference between the "canned lecture" and the one recorded on the field, is essential to make the learning experience though the video most similar with the one that is available in class. This is not just our opinion, but a fact that has been proved by an interesting investigation by Fritze and Nordkvelle [7].

Moreover, this solution also dramatically reduces costs, since, under the conditions we discussed at the beginning of this section, i.e. if the course's content is stable, videos can be recorded during one academic year and used during the next one. Hence no extra work is required on the teacher side, and recording cost can be minimal, as discussed in [6].

\section{THE EXPERIMENT AND ITS EVALUATION}

Our starting point was the availability of lectures of an introductory programming course that were recorded two years ago. The course is about object oriented program- ming, and the programming languages that are used to introduce and discuss the concepts are Java and C++ (with more emphasis on the first one). An especially challenging lecture was the one on the Java Collections framework, which makes a heavy use of the concept of Interface, which was new to the students. In the current academic year (2008-09), at the right time, instead of giving the frontal lecture on Java Collections we decided to require the students to take that lecture through the available videos of a the previous edition of the course before coming to class.

The lecture in class was then centred on a collective discussion. The teacher inquired about the key points, verified the students' understanding, and explained some issues. The teacher's impression was excellent: it really looked like most students were reaching a much deeper understanding of the key concepts through this interactive session.

The point was now to verify what the students thought about this different style.

To this mean we prepared an anonymous survey through surverymonkey. Students had to express their agreement with a set of sentences. Out of the approximately 60 students who were present in the classroom, 38 decided to respond to the questionnaire.

Four sentences regarded a comparison between the traditional frontal lecture and our proposed model, and were evaluated on a 4 points Likert Scale. The following table reports the sentences and the relative results.

TABLE I.

\begin{tabular}{|c|c|c|c|c|}
\hline $\begin{array}{c}\text { Traditional lectures are better } \\
\text { because... }\end{array}$ & 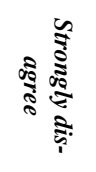 & 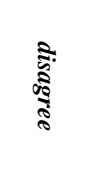 & ถి & 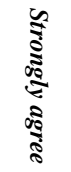 \\
\hline ... watching videos is boring & $21.1 \%$ & $50.0 \%$ & $23.7 \%$ & $5.3 \%$ \\
\hline $\begin{array}{l}\text {... the workload of having to watch } \\
\text { the lecture in advance is too much }\end{array}$ & $18.4 \%$ & $52.6 \%$ & $26.3 \%$ & $2.6 \%$ \\
\hline $\begin{array}{l}\ldots \text { I prefer not to be involved in a } \\
\text { discussion in classroom }\end{array}$ & $31.6 \%$ & $50.0 \%$ & $15.8 \%$ & $2.6 \%$ \\
\hline $\begin{array}{l}\ldots \text { the discussion does not improve } \\
\text { much the understanding }\end{array}$ & $57.9 \%$ & $28.9 \%$ & $13.2 \%$ & $0.0 \%$ \\
\hline
\end{tabular}

All these responses showed an appreciation of the new model ranging between $70 \%$ and $85 \%$. The probably obvious but most striking result is that students felt the discussion in class really makes an important difference. Also, the fact that by far most student did not consider boring or too much work having to watch the video in advance was somehow surprising to us.

TABLE II.

\begin{tabular}{|c|c|c|c|c|}
\hline $\begin{array}{c}\text { Traditional lectures are better } \\
\text { because... }\end{array}$ & 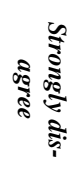 & 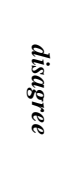 & ถి & 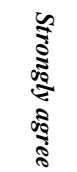 \\
\hline $\begin{array}{l}\text {... get deeper into the presented } \\
\text { concepts }\end{array}$ & $0.0 \%$ & $10.5 \%$ & $50.0 \%$ & $39.5 \%$ \\
\hline ...understand better in general & $2.6 \%$ & $13.2 \%$ & $44.7 \%$ & $39.5 \%$ \\
\hline ...have a better participation & $0.0 \%$ & $7.9 \%$ & $55.3 \%$ & $36.8 \%$ \\
\hline
\end{tabular}


The agreement is embarrassingly high, going from $85 \%$ to $92 \%$.

Finally, the last set of sentences tried to identify what is believed to be the best structure for the classroom discussion. This time we used a 5 points Likert Scale, with a neutral item. Table 3 reports the results.

TABLE III.

\begin{tabular}{|c|c|c|c|c|}
\hline $\begin{array}{l}\text { The discussion in the classroom } \\
\text { should... }\end{array}$ & 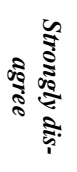 & ڤ్రి & ถి & 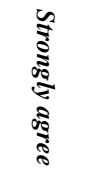 \\
\hline $\begin{array}{l}\ldots \text { follow the logical structure of } \\
\text { the video lecture, repeating the } \\
\text { concepts and allowing to discuss } \\
\text { and deepen them }\end{array}$ & $0.0 \%$ & $2.6 \%$ & $15.8 \%$ & $44.7 \%$ \\
\hline $\begin{array}{l}\text {...be based on examples that are } \\
\text { close to the concepts but are differ- } \\
\text { ent from what was discussed in the } \\
\text { videos }\end{array}$ & $0.0 \%$ & $7.9 \%$ & $23.7 \%$ & $36.8 \%$ \\
\hline
\end{tabular}

Here the responses are less interesting, even though they confirm the role of the discussion. Probably we should have phrased the set of statements in a more significant way.

Seven students gave free comments. Four of them essentially did not add much to the above results, explicitly confirming the appreciation for the experiment. One comment expressed a strong preference for the traditional way of lecturing "because it is more serious and more suited to an academic environment”. The last two comments expressed appreciation for the experiment, but were skeptical about the possible application of the method to a whole course.

\section{RELATED WORK}

After the present paper was accepted for publication, we stumbled into a few papers that presented a similar approach.

Lage et al. [8] introduced in 2000 the concept of "the inverted classroom”, and applied it to a course in Microeconomics. The idea was that students had to read assignments or, where available, watch videotapes or PowerPoint presentations before coming to class. Lectures were then dedicated to question answering and/or to economics experiments. The authors claim that such approach is suited to all learning styles because it blends a variety of different approaches. They investigated students and teachers satisfaction, and report that the perception of both students and instructors were positive.

Independently, Foertsch et al. [9] came in 2002 to the same idea. They also started from the need of moving towards a learn-by-doing paradigm, and encountered the hurdle that "before students can be effective team members or problem-solvers, they need to have a basic understanding of the problem domain, some background knowledge about how problems can be solved, and instruction on how to use the tools at their disposal". So they tried to use "distance technology" to actually reduce the distance between students and professors. The vision was that if all of a professor's lectures, syllabi, and assignments are digitized and put online, professors could spend less of their time lecturing and more time assisting the students. This approach was experimented with a course and reported in their work. As a result, "the replacement of live lectures with online lectures and Team Labs significantly enhanced the usefulness, convenience, and value of the course for the majority of students".

Day \& Foley [10] came autonomously to the same thought, and reported similar results. They run in parallel two different classes, one in a traditional way and the other by asking students to preview presentations prepared with Microsoft Producer. Their results show that students in the second set outperformed by the ones in the first set.

\section{CONCLUSIONS}

We presented our experiment in which lectures that were recorded in the classroom are used as introductory material that students are supposed to view and understand before coming to class. In this way the whole time in class can be devoted to open discussion, collective exercises, challenges proposed to the students, clarification of doubts and difficult points and question answering. The model we propose, and that we experimented in our trial, allows a much higher level of interactivity among students and teacher, and doubles the time students spend with the teacher (half of this time being virtualized by videos).

Although the model per se is similar to the approach in which one asks students to read material before coming to class, we emphasize that in our proposal the material that the students have to go through before coming to class is exactly tailored on what the teacher thinks is the best, because it corresponds to the lectures that he gives, and therefore perfectly matches, by definition, his style and stresses exactly those arguments that he thinks are most relevant. Such a perfect match is difficult to achieve through simple reading. Moreover, the production cost is close to zero, because the recording is done during lectures that take place anyway. In our case, using the LODE video acquisition system that we developed, the teacher can even record himself, so that production costs are really zero. (We actually successfully experimented with selfrecording).

After performing our experiment, we found that similar ideas had already been expressed in the past in three papers that were unaware of each other, probably because the results were presented to specific communities (Economics education, Engineering education, HumanComputer Interaction) and did not reach a broader audience.

The students' feedback on the experiment we run is quite encouraging. It shows that the idea of re-using with different purpose videos that were intended as support for individual study is perceived by the students as effective and can actually bring to a more interesting teaching. We are not yet able to judge if, beyond the perception, this different methodology actually achieves better results in terms of actual understanding, and ultimately in terms of better students' performances.

We therefore interpret this result as a positive response to a feasibility study: next year we intend to run this experiment on a larger scale. Instead of limiting our trial to a single lecture, we shall use this methodology for most of the course. At the end we will be able to quantitatively measure the results in a controlled experiment, by checking if there is an improvement in the exams outcomes with respect to the average results of the last few years (which 
seem to be quite stable). To this purpose, we are this year re-recording all lectures of the introductory course on Object Oriented Programming. Next year we will ask students to view these lectures before coming to class (at least for most of the lectures). In class we shall propose ad hoc exercises and stimulate collective discussions.

Of course such model is not universally applicable. For instance, it would be impossible to apply it to courses that change from one year to the next (e.g. because they rely on evolving technologies, or because they're close to research topics).

As we discussed, substituting the idea of recording live video-lectures with ad-hoc prepared material would be much more costly. Moreover, it is would be less effective because a real lecture is more likely to have the right pace, since teachers have a constant feedback from the students' faces about the level of clarity or difficulty and can adapt to it.

In summary, we believe that a creative and nonconventional use of recorded digital videos can be helpful in promoting a more interesting and interactive teaching style.

\section{REFERENCES}

[1] Haataja, A., Kontkanen, S., Suhonen, J. \& Sutinen, E. (2001). Teaching University-Level Computer Science to High School Students over the Web. Proceedings of ED-MEDIA 2001, AACE (Chesapeake) , pp. 630-635,

[2] Ronchetti, M. "Using the Web for diffusing multimedia lectures: a case study”. In D. Lassner \& C. McNaught (Eds.), Proceedings of ED-MEDIA 2003, AACE (Chesapeake) pp. 337-340.

[3] Carbonaro, A. "Ontology-based video annotation and recommendation in a semantic education framework” In: The Semantic Web - ASWC 2006 Workshop Proceedings, Li G., Liang Y., Ronchetti
M. eds., Changchun, Jilin, China:Jilin University Press, 2006. (available on line at http://jeromedl4eastweb.deri.ie/resource/tIZ2Q9Tk

[4] Mohamed Ally. "Foundations of Educational Theory for Online Learning”, In The Theory and Practice of Online Learning, Terry Anderson, Ed., May 2008.

[5] Siemens, G. Connectivism. "A learning theory for the digital age”. Int. J. of Instructional Technology \& Distance Learning, 2(1). (2005). (Available online at: http://www.itdl.org/Journal/Jan_05/article01.htm)

[6] Ronchetti, M. "The impact of Internet-carried video-lectures on education". To be published

[7] Fritze Y. \& Nordkvelle Y. "Comparing Lectures - Effects of the Technological Context of the Studio”. In: Education and Information Technologies, Kluwer Academic Publisher, Netherland, (2003) pp. 327-343

[8] Lage, M.J., Platt, G.J. \& Treglia M. "Inverting the Classroom: A Gateway to Creating an Inclusive Learning Environment" The Journal of Economic Education, Vol. 31, No. 1, (2000) pp. 30-43

[9] Foertsch J.. Moses G., Strickwerda J. \& Litzkov M "Reversing the lecture/homework paradigm using eTEACH web-based streaming video software”. Journal of Engineering Education vol. 91 (3) (2002) pp. 267-274

[10] Day J.\& Foley J.. "Evaluating web lectures: a case study from HCI”. CHI 2006 - Experience Report - User Centered Design for Learning and Education (2006) pp.195-200

\section{AUTHORS}

M.Ronchetti is an associate professor in Computer Science at the Università di Trento, Italy. (e-mail: marco.ronchetti@unitn.it).

This article was modified from a presentation at the International Conference of Interactive Computer Aided Learning ICL2009, September 2009 in Villach, Austria. Submitted December $1^{\text {st }}$, 2009. Published as resubmitted by the author February 12, 2010. 